\title{
Cooking fuels and respiratory symptoms in kitchen workers in Morogoro Municipality, Tanzania
}

\author{
Agnes MAHEMBE $^{1}$, Stelyus L. MKOMA ${ }^{2 *}$ and Joyce L. KINAMBO ${ }^{1}$ \\ Department of Food Science and Technology, Faculty of Agriculture, Sokoine University of Agriculture \\ (SUA), P.O. Box 3006, Morogoro, Tanzania. \\ 2 Department of Physical Sciences, Faculty of Science, Sokoine University of Agriculture (SUA), P.O. Box \\ 3038, Morogoro, Tanzania. \\ * Corresponding author, E-mail: stelyusm@gmail.com; mkoma@suanet.ac.tz; Tel.: +255232603404,
} Fax: +255232603404

\begin{abstract}
Few studies on a possible association between cooking fumes from different fuels and respiratory diseases other than cancer have been reported earlier. In the present study, an attempt was made to find out various respiratory symptoms in 360 kitchen workers using different cooking fuels. The study was conducted between October 2009 and March 2010 and consisted of 234 females and 126 males. The kitchen workers from 104 selected kitchens in hotels, fast food restaurants, institution, food vendors and in households of the general population were interviewed using a questionnaire. Information on the presence of dry cough, productive cough, running nose, irritation of nose or eyes, and chest pain in connection with work were asked. The overall respiratory symptoms were observed in $68.9 \%$ of the surveyed kitchen workers. With the exception of dry cough, females encountered $61.54 \%$ of productive cough, $57.69 \%$ running nose, and $71.28 \%$ irritation of nose or eyes. Chest pain and irritation of nose and eyes were more common in kitchen workers that use biomass fuel, charcoal and/or kerosene than other cooking fuels. The results of the study indicate a significant relationship $(\mathrm{p}<0.05)$ between use of different cooking fuels and respiratory symptoms. However, further studies are needed to support the present results.
\end{abstract}

(c) 2010 International Formulae Group. All rights reserved.

Keywords: Kitchen work; cooking fuels; Respiratory infection; Cooks

\section{INTRODUCTION}

Cooking is one of the important functions for the human life. The number of hours spent in the kitchen for domestic work and cooking is variable depending on the burden of extra work. On an average, kitchen workers spend about six hours in the kitchen daily for cooking food and other purposes.
The location of the kitchen, the type of ventilation, and the type of fuel used play a significant role on health (Boadi and Kuitunen, 2006). It is estimated that a majority of the world's population $(50 \%)$ and around $75 \%$ of those living in developing countries rely on traditional biomass fuels as the major source of domestic energy (Reddy 
et al., 2004). In Tanzania, biomass fuels account for more than $90 \%$ of primary energy supply (Kilabuko et al., 2007a). However, recent development has been accompanied by a transition away from traditional biomass fuels to modern fuels (usually charcoal, kerosene, liquified petroleum gas, and electricity). This transition in cooking fuel selection allows comparison of a number of respiratory diseases such as respiratory infections of individuals who cook with different types of fuels.

Investigations in different part of the world have shown that kitchen workers in hotels and restaurants may have an increased risk of lung cancer and an increased mortality from respiratory diseases (Svendsen et al., 2003; Behera and Balamugesh, 2006). Several studies have indicated that respiratory symptoms and increased risk of respiratory cancer may be associated with exposure to cooking fumes (Ezzati and Kammen, 2001a,b; Smith et al., 2004; Mishra et al., 2005). Food is prepared under high temperatures, especially when grilled or fried. Harmful degradation products may be formed during such processes (Robinson et al., 2006) and can produce various respiratory symptoms such as irritation in the airways (Svendsen et al., 2003).

In Tanzania, the use of gas and electricity for cooking is not common. Charcoal and kerosene are other fuels widely used after biomass fuels and are skewed towards urban areas while biomass fuels are heavily used in rural areas (MEM, 2003). Few studies in Tanzania are available for respiratory infections among different groups or workers (Kayumba et al., 2007; Kilabuko et al. 2007a,b) and there have been no previous investigations on kitchen workers of a possible association between exposure to cooking fumes and respiratory infections. The aim of this study was to find out various respiratory symptoms in kitchen workers using different cooking fuels in Morogoro Municipality.

\section{MATERIALS AND METHODS}

In cooperation with the kitchen managers, head of institutions and the kitchen workers of 104 kitchens in Morogoro Municipality were asked to have their businesses (organization or firm) or institutions or households included in the study. A total of 360 kitchen workers of the selected kitchens were interviewed using a structured questionnaire. Of those, $24.17 \%$ worked in hotel, $26.94 \%$ in fast-food restaurants, $22.50 \%$ in institution, and $12.50 \%$ in food vendors and $13.89 \%$ in household kitchens from the general population. Among information requested in the questionnaire were how long have they been working as chef, time spend in kitchen per day, and questions about respiratory symptoms in connection with work. The survey also gathered information on fuel type used for cooking by the selected kitchens. To elicit this information, the question "what type of fuel does your kitchen usually use for cooking?" was asked. The question was then followed by a list of different fuel names to choose from. Information on cooking fuel types was used to categorize kitchen workers into groups from kitchens using biomass fuels (firewood, straw, dung and crop residues), charcoal, kerosene, electricity; and group of kitchen workers from kitchens using LPG. Observation was also done to check the kitchen design if was open to or closed from the public, the type of exhaust system and ventilation. The interview of the respondents from the households in the general population was based on the assumption the interviewee is the principal cook in the house. Kitchen workers with smoking habits were excluded from the study.

The outcome of the study was the presence of the respiratory symptoms among kitchen workers. Symptoms were defined as dry cough, productive cough, running nose, 
nose/eyes irritation and chest pain. The respondent was regarded as having cough if he or she had reported periods with daily cough. The respondent was regarded as having running nose if he or she reported any form of flu. Symptoms during work were considered to be present if the respondent reported to have had any respiratory symptom, such as irritation in the nose or eyes, running nose, or cough in connection with work during the last two weeks.

A coded structured questionnaire was analysed using the statistical package for social sciences (SPSS) software version 12 for windows and excel. Multinomial logical regression analysis was applied for data analysis for establishing the relationship between the different possible predictors (fuel types) for respiratory symptoms and the outcome variables: dry cough, productive cough, running or blocked nose, throat or nose or eye irritation and chest pain. In that analysis, each predictor was tested separately and the levels of statistical significance were set to $\mathrm{p}<0.05$ for entering the variables and to $\mathrm{p}>0.1$ for removing a variable. Also in present context, infections were considered to be present if the kitchen workers reported to have had the symptoms during the last two weeks.

\section{RESULTS}

The descriptive characteristics for kitchen workers are shown in Table 1 and the study sample consisted of 234 females $(72.96 \%)$ and 126 males $(27.03 \%)$. The results of the socioeconomic status of the kitchen workers in Morogoro Municipality showed notable disparities as shown in Table 1 . The mean age were 31 years (range: 14 - 46 years) for females and 28 years (range: 18 - 50 years) for males. Most of the kitchen workers $(53.51 \%)$ had primary school education, while $32.19 \%$ had secondary school education. The kitchen workers have been working in kitchen for at least six months and they spend more than four hours in kitchens (i.e. $61.84 \%$ for kitchen workers). While most of the studied employed kitchen workers earn less than 100,000 Tanzanian shillings (TAS) per month, the source of their income comes from salaries with less contribution from other income generating activities.

\section{Prevalence of respiratory symptoms}

Out of a total sample of 360 kitchen workers who were surveyed for the presence of respiratory symptoms, $248 \quad(68.89 \%)$ workers showed the presence of the symptoms. The results also show that 67 $(59.82 \%)$ female and $45(40.18 \%)$ male kitchen workers did not show a sign for the presence of respiratory symptoms in connection with work. The prevalence of the respiratory symptoms for the kitchen workers are given in Table 2. The results show that the prevalence of productive cough, running nose, irritation of nose or eyes and chest pain was higher $(\mathrm{p}<0.05)$ in female than male, but the prevalence of dry cough was higher for the males than for the females. A possible explanation may be because females in general are more frequently employed in this job and also due to socio-cultural reasons that females are more exposed to the fuel and at an early age than males.

\section{Association between respiratory symptoms and the types of cooking fuels}

Table 3 shows different types of respiratory symptoms encountered by different cooking fuel users. It was observed that there was a significant relationship ( $\mathrm{p}<$ 0.05 ) between the use of cooking fuels and respiratory symptoms. There were mainly five types of cooking fuels used by these kitchen workers: biomass fuels; charcoal/kerosene; electricity; liquified petroleum gas; and mixed fuels such as a combination of two or more cooking fuels. It was observed that all types of cooking fuels showed prevalence of respiratory symptoms (i.e. dry cough, 
productive cough, running nose, irritation of nose or eyes, and chest pain) during the surveyed period. The overall in all categories of cooking fuels the respiratory symptoms were higher $(79 \%)$ in kitchen workers who use charcoal and/or kerosene (Figure 1). About $5 \%$ of biomass fuel users and $3 \%$ of electricity users also encountered various respiratory symptoms. Figure 1 also shows that $6 \%$ of the kitchen workers using mixed cooking fuels showed respiratory symptoms. Our present study showed an overall higher prevalence of chest pain and irritation of nose or eyes of $40.11 \%$ and $41.18 \%$ respectively and other respiratory symptoms among charcoal and/or kerosene users than other cooking fuel users. It should also be noted that LPG users, which is considered traditionally to be safe fuel, also produces a significant prevalence of respiratory symptoms.

\section{Kitchen characteristics and the respiratory symptoms}

Table 4 presents the key selected matching kitchen characteristics such as the construction materials and layout of kitchen for the five respiratory symptoms: dry cough, productive cough, running nose, irritation of nose or eyes and chest pain. Kitchen design, floor type and presence of chimney were essentially different and could be associated with the observed respiratory symptoms. The floor materials and kitchen design believed to be important indicators of socioeconomic status, demonstrated an extremely strong association with respiratory symptoms. The prevalence of all five symptoms among kitchen workers in kitchens with dirt floors was substantially higher than those kitchen workers in kitchens with cement or tiles floors. It should also be noted that chest pain and irritation of nose or eyes where the most observed respiratory symptoms associated with the kitchen characteristics.

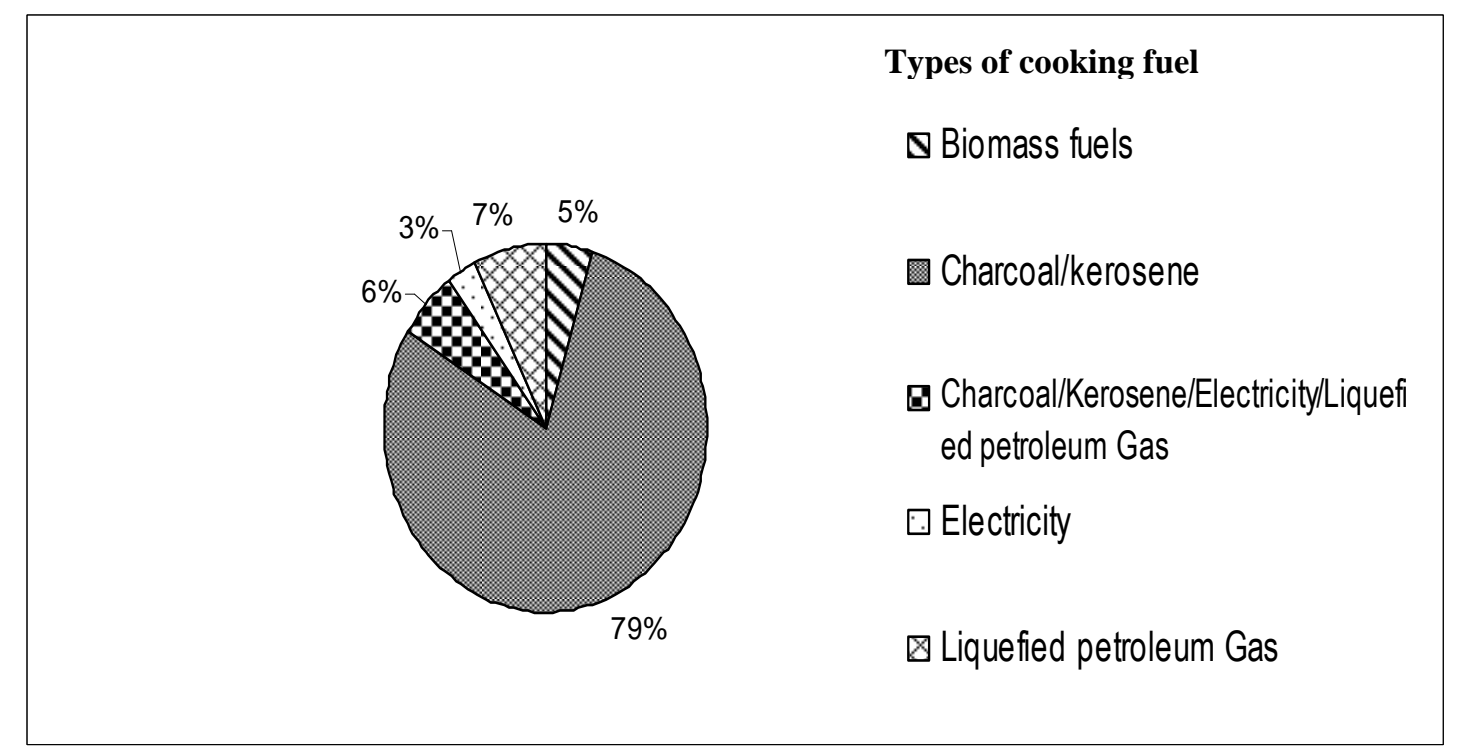

Figure 1: Kitchen workers reporting respiratory symptoms by types of cooking fuel. 
Table 1: Descriptive characteristics of the kitchen workers in Morogoro Municipality.

\begin{tabular}{lcc}
\hline Characteristics & \multicolumn{2}{c}{ Kitchen workers } \\
\hline & Frequency & Percentage (\%) \\
\hline Sex & 126 & 27.03 \\
Male & 234 & 72.965 \\
Female & & \\
Age & 85 & 28.805 \\
$18-25$ & 159 & 48.29 \\
$26-35$ & 106 & 20.45 \\
$36-46$ & 10 & 2.45 \\
$>46$ & & \\
Education & 19 & 6.415 \\
No formal education & 207 & 53.515 \\
Primary & 106 & 32.19 \\
Secondary & 28 & 7.87 \\
Post secondary & & \\
Number of months/years in job & 95 & 29.58 \\
6 months -1 year & 265 & 70.42 \\
> year & & \\
Hours in the kitchen per day & 9 & 1.45 \\
< 2hr & 134 & 36.71 \\
3-4 hrs & 217 & 61.84 \\
> 4hrs & & \\
Income per month & 260 & 80.515 \\
Less than 100000 & 100 & 19.48 \\
100000-250000 & & \\
Other income generating activities & 17 & 2.74 \\
Farming & 49 & 7.9 \\
Animal keeping & 65 & 77.19 \\
Small businesses & 229 & \\
None & & \\
\hline
\end{tabular}

Table 2: Prevalence of respiratory symptoms among kitchen workers by gender.

\begin{tabular}{lcccccc}
\hline Respiratory & \multicolumn{2}{c}{ Female } & \multicolumn{2}{c}{ Male } & \multicolumn{2}{c}{ Total } \\
\cline { 2 - 7 } Infection & Frequency & Percentage & Frequency & Percentage & Frequency & Percentage \\
\hline Dry cough & 9 & 47.37 & 10 & 52.63 & 19 & 7.66 \\
Productive & 8 & 61.54 & 5 & 38.46 & 13 & 5.24 \\
cough & 15 & 57.69 & 11 & 42.31 & 26 & 10.48 \\
Running nose & 67 & 71.28 & 27 & 28.72 & 94 & 37.90 \\
Nose/eyes & 67 & 70.83 & 28 & 29.17 & 96 & 38.71 \\
irritation & 68 & & & & & \\
Chest pain & & &
\end{tabular}


Table 3: Prevalence of respiratory symptoms in kitchen workers by types of fuel.

\begin{tabular}{llccc}
\hline Types of Cooking Fuel & Respiratory Symptoms & Frequency & Percentage & $\begin{array}{c}\text { p- } \\
\text { Value }\end{array}$ \\
\hline Biomass fuels & Dry Cough & - & - & - \\
& Productive Cough & 1 & 9.09 & 0.75 \\
& Nose/eyes irritation & 4 & 36.36 & 0.04 \\
& Chest pain & 6 & 54.55 & 0.02 \\
\hline Charcoal/Kerosene & Dry Cough & 14 & 7.49 & 0.04 \\
& Productive Cough & 8 & 4.28 & 0.62 \\
& Running Nose & 13 & 6.95 & 0.94 \\
& Nose/eyes irritation & 77 & 41.18 & 0.03 \\
& Chest pain & 75 & 40.11 & 0.01 \\
\hline Charcoal/Kerosene/ Electricity/LPG & Dry Cough & 2 & 14.29 & - \\
& Productive Cough & 4 & 28.57 & 0.03 \\
& Running nose & 1 & 7.14 & 0.24 \\
& Nose/eyes irritation & 3 & 21.43 & 0.92 \\
& Chest pain & 4 & 28.57 & 0.03 \\
\hline Electricity & Dry Cough & 1 & 14.29 & 0.87 \\
& Running nose & 1 & 14.29 & 0.37 \\
& Nose/yes irritation & 2 & 28.57 & 0.24 \\
& Chest pain & 3 & 42.86 & 0.99 \\
\hline Liquefied petroleum gas & Dry Cough & 2 & 11.76 & - \\
& Running nose & 1 & 5.88 & - \\
& Nose/eyes irritation & 6 & 35.29 & - \\
& Chest pain & 47.06 & - \\
\hline
\end{tabular}

Table 4: Distribution of kitchen structure by respiratory symptoms.

\begin{tabular}{|c|c|c|c|c|c|c|c|c|c|c|}
\hline \multirow[b]{2}{*}{ Kitchen design } & \multicolumn{2}{|c|}{ Dry Cough } & \multicolumn{2}{|c|}{$\begin{array}{c}\text { Productive } \\
\text { Cough }\end{array}$} & \multicolumn{2}{|c|}{$\begin{array}{c}\text { Running } \\
\text { Nose }\end{array}$} & \multicolumn{2}{|c|}{$\begin{array}{l}\text { Nose/Eye } \\
\text { Irritation }\end{array}$} & \multicolumn{2}{|c|}{ Chest Pain } \\
\hline & $\mathrm{N}$ & $\%$ & $\mathrm{~N}$ & $\%$ & $\mathrm{~N}$ & $\%$ & $\mathrm{~N}$ & $\%$ & $\mathrm{~N}$ & $\%$ \\
\hline \multicolumn{11}{|l|}{ Wall material } \\
\hline Rough cement & 10 & 7.87 & 6 & 4.72 & 17 & 13.39 & 42 & 33.07 & 52 & 40.94 \\
\hline Smooth cement & 6 & 9.84 & 6 & 9.84 & 3 & 4.92 & 25 & 40.98 & 21 & 34.43 \\
\hline Mud bricks & 5 & 10.64 & 1 & 2.13 & 6 & 12.77 & 16 & 34.04 & 19 & 40.43 \\
\hline Wood & - & - & - & - & - & - & 13 & - & - & - \\
\hline \multicolumn{11}{|l|}{ Floor material } \\
\hline Dirt cement & 6 & 6.12 & 8 & 8.16 & 11 & 11.22 & 39 & 39.80 & 34 & 34.69 \\
\hline Poured cement & 6 & 18.18 & - & - & 3 & 9.09 & 12 & 36.36 & 12 & 36.36 \\
\hline Soil/earth & 2 & 3.13 & 1 & 1.56 & 6 & 9.38 & 23 & 35.94 & 32 & 50.00 \\
\hline Tiles & 6 & 11.32 & 4 & 7.55 & 6 & 11.32 & 15 & 28.30 & 22 & 41.51 \\
\hline \multicolumn{11}{|l|}{ Kitchen design } \\
\hline Enclosed indoor & 17 & 8.02 & 11 & 5.19 & 22 & 10.38 & 86 & 40.57 & 76 & 35.85 \\
\hline Open outdoor & 3 & 8.33 & 2 & 5.56 & 4 & 11.11 & 12 & 33.33 & 15 & 41.67 \\
\hline \multicolumn{11}{|l|}{ Chimney } \\
\hline Absent & 18 & 7.89 & 13 & 5.70 & 26 & 11.40 & 86 & 37.72 & 85 & 37.28 \\
\hline Present & 2 & 10.00 & - & - & - & - & 8 & 40.00 & 10 & 50.00 \\
\hline
\end{tabular}




\section{DISCUSSION}

The surveyed kitchens in the present study included popular dining places in the municipal such as the best run firms in hotels, institutions, fast food restaurants, food vendors and kitchens in households of the general population. There were mainly five types of cooking fuels used by these surveyed kitchen workers: biomass fuel; charcoal/kerosene; mixed fuels, electricity and liquified petroleum gas. The results showed that all types of cooking fuels produce respiratory symptoms such as dry cough, productive cough, running nose, irritation of nose or eyes and chest pain among kitchen workers. Kitchen design, floor type and presence of chimney were essentially different and could be associated with the observed respiratory symptoms. Compared to the male kitchen workers, the results showed that female kitchen workers have higher percentage of the prevalence of all respiratory symptoms except dry cough. A possible explanation may be because females in general are more frequently employed in this job and also due to socio-cultural reasons that females are more exposed to the fuel and at an early age than males. It was also observed that kitchen workers who use charcoal and/or kerosene encountered more of the respiratory symptoms than other fuels. The symptomatic kitchen workers had higher prevalence of chest pain and irritation of nose or eyes among biomass fuel and charcoal/kerosene user groups $(\mathrm{p}<0.05)$. The higher prevalence of productive cough and chest pain $(\mathrm{p}<0.05)$ were common to kitchen workers who use mixed fuels. On the other hand, there were no significant differences between the respiratory symptoms in this study $(p>0.1)$ for the electricity users.

This finding is consistent with other studies reported the associated exposures to pollutants from these fuels and respiratory infections (Ezzati and Kammen, 2001a; Smith et al., 2004; Kilabuka et al., 2007b). In this study, we provide additional evidence that the use of different types of fuels increases the risk of respiratory symptoms among kitchen workers. The respiratory symptoms were assessed by the use questionnaire which required kitchen workers to explain on their health with respect to respiratory symptoms in the period two weeks prior to the survey. Since this is not an objective way of collecting health information, the method used might have explained the discrepancies in the study results.

\section{Conclusion}

The absence of indoor air quality guidelines in Tanzania increases the risk of continuous exposure to kitchen workers. The use of different cooking fuels and association with respiratory symptoms in Morogoro municipality has been studied. The results showed that there was a significant relationship $(\mathrm{p}<0.05)$ between use of different cooking fuels and respiratory symptoms. The results also showed than chest pain and irritation of nose or eyes were common in biomass fuel and charcoal/kerosene users. The results obtained from this study are novel and should serve as a warning to local and national authorities and a starting point for further research in other metropolises in the country. However, the study does not answer the question as to which particular components and at what levels of exposure in the cooking fumes give rise to the observed respiratory symptoms. More research is therefore needed to support the present results.

\section{ACKNOWLEDGEMENTS}

The authors gratefully acknowledge the cooperation and helping hands of the managers and head of institutions of the kitchens surveyed. We also thank kitchen workers who willingly took part in this study. We acknowledge the financial support of the Higher Education Learning Board (HELB) of Tanzania to the first author.

\section{REFERENCES}

Behera D, Balamugesh T. 2006. Doseresponse relationship between cooking fumes exposures and lung cancer among 
Chinese nonsmoking women. Cancer Res., 66: 4961 - 4967.

Boadi KO, Kuitunen M. 2006. Factors affecting the choice of cooking fuel, cooking place and respiratory health in the Accra metropolitan area, Ghana. J. Biosocial Sci., 38: 403-412.

Ezzati M, Kammen DM. 2001a. Indoor air pollution from biomass combustion and acute respiratory infections in Kenya: an exposure-response study. The Lacent, 358: 619-624.

Ezzati M, Kammen DM. 2001b. Quantifying the effects of exposure to indoor air pollution from biomass combustion on acute respiratory infections in developing countries. Environ. Health Perspective, 109: 481-489.

Kayumba A, Bråtveit M, Mashalla Y, Moen B. 2007. Acute respiratory symptoms among sisal workers in Tanzania. Occup. Med. (Lond.), 57: 290-293.

Kilabuko JH, Matsuki H, Nakai S. 2007a. Air quality and acute respiratory illness in biomass fuel using homes in Bagamoyo, Tanzania. Int. J. Environ. Res. Public Health, 4(1): 39-44.

Kilabuko JH, Nakai S. 2007b. Effects of Cooking Fuels on Acute Respiratory Infections in Children in Tanzania. Int. J. Environ. Res. Public Health, 4(4): 283288.
Ministry of Energy and Minerals (MEM) of the United Republic of Tanzania. 2003. National Energy Policy, Government printer, Dar es Salaam.

Mishra M, Smith KR, Retherford RD. 2005. Effect of cooking smoke and environmental tobacco smoke on acute respiratory infections in young Indian children. Pop. Environ., 26(5): 375-396.

Reddy TS, Guleria R, Sinha S, Sharma SK, Pande JN. 2004. Domestic Cooking Fuel and Lung Functions in Healthy Nonsmoking Women. Indian J. Chest Dis. Allied Sci., 46: 85-90.

Robinson AL, Subramanian R, Donahue NM, Bernardo-Bricker A, Rogge WF. 2006. Source apportionment of molecular markers and organic aerosol. 3. Food cooking emissions. Environ. Sci. Technol., 40: 7820-7827.

Smith KR, Mehta S, Maeusezahl-Feuz M. 2004. Indoor air pollution from household use of solid fuels. In Comparative Quantification of Health Risks: Global and Regional Burden of Disease Attributable to Selected Major Risk Factors, Ezzati M (ed). World Health Organisation: Geneva.

Svendsen K, Sjaastad AK, Siverstsen I. 2003. Respiratory symptoms in kitchen workers. Am. J. Ind. Med., 43: 436 - 439 